\title{
Presentación del dossier Género y Cultura Colonial
}

Introduction dossier Gender and Colonial Culture

Silvia Ruiz Tresgallo

Universidad Autónoma de Querétaro, México

ruiztresgallosilvia@gmail.com

DOI: https://doi.org/10.11144/Javeriana.cl25.gycc

ORCID: https://orcid.org/0000-0001-8072-3521

Recibido: 28 abril 2019

Aceptado: 28 julio 2019

Publicado: 13 octubre 2021

Este dossier forma parte del proyecto de investigación "Voces silenciadas por la historia: la mujer en la literatura y la producción cultural del barroco americano" registrado para el periodo 2019-2021 en la Universidad Autónoma de Querétaro (México), cuenta con el apoyo externo del Prodep y fue dirigido por Silvia Ruiz Tresgallo. Dentro de las labores de revisión de los artículos incluidos en este dossier han participado las estudiantes María Valentina Díaz Herrera (Licenciatura en Lenguas Modernas Inglés, UAQ) y Mayra Hernández Ávila (Maestría en la Enseñanza de los Estudios Literarios, UAQ).

El periodo colonial, que transcurre en el espacio americano del siglo XVI hasta principios del siglo XIX, no solo supone una continuación de los valores impuestos por Europa en las tierras conquistadas, sino que nos revela características propias, es decir, alteraciones significativas fruto de las oportunidades que surgen en este entorno particular. Por una parte, los colonizadores impusieron una sociedad patriarcal donde la mujer, en general, es construida como un ser dependiente que no tiene voz ni capacidad para el pensamiento profundo. Sin embargo, la dificultad para vigilar los cuerpos que habitaban un territorio tan vasto permitió una libertad, en especial en el ser femenino, que generó autorreflexiones y posicionamientos divergentes a la cultura dominante. Por otra parte, la diversidad sexo-genérica que aceptaban y visibilizaban determinados pueblos indígenas debió causar no poca sorpresa entre los peninsulares, que procedían de una sociedad mucho más reprimida y represora en este campo. Según los estudios de Águeda Gómez Suárez sobre el espacio americano, "se puede concluir que las observaciones hechas por los cronistas coloniales y los patrones culturales actuales apuntan a que existía una cultura sexual diversa y heterogénea, donde la ambigüedad genérica y las prácticas homoeróticas eran frecuentes" (39). Desde una mirada europea, solo los dioses del mundo grecorromano podían desafiar la construcción binaria del género o establecer relaciones sexuales que cuestionaban la heteronorma. Sobre este asunto nos habla Margarita Moreno Conde, quien, al observar las fuentes de la antigua Grecia, llama la atención sobre "el elevado número de casos de cuerpos que mutan, pasando del sexo femenino al masculino o viceversa" (66), sin olvidar la ambigüedad que nos ofrece la figura de Hermafroditos, el cual reúne ambos sexos. En el periodo histórico que nos ocupa, la Inquisición, creada para mantener la pureza de la fe católica, se encargaba tanto de invisibilizar estas disidencias, al describirlas por medio de la excepcionalidad o la rareza, como de criminalizarlas y castigarlas por medio de su brazo represor. Sin embargo, el barroco americano, caracterizado por las tensiones entre la cultura dominante y las culturas dominadas, también ofrece espacios fluidos que permiten negociar construcciones y significados.

Dado el desarrollo y pertinencia actual de los estudios de género, nosotros nos preguntamos qué rupturas, alianzas y alteraciones a la cultura peninsular propone el espacio colonizado. Consideramos que este territorio, a todas luces más amplio y diverso que Castilla, cuestiona las categorías impuestas y genera nuevas dinámicas de poder y, por ende, maneras innovadoras de entender al ser humano. Nos planteamos que, aunque la teoría de género se ha desarrollado en especial durante los siglos XX y XXI, una mirada al pasado desde esta perspectiva contemporánea nos permite visibilizar tanto las violencias que sufren los habitantes del espacio 
americano como las resistencias que producen. Nuestro dossier explora en profundidad la relación que existe entre la construcción social del género y la cultura del periodo colonial a través de una serie de ensayos de gran variedad temática que, aunque pertenecen a líneas de investigación distintas, comparten una mirada crítica similar.

Sin duda, uno de los objetivos de este volumen es visibilizar la aportación de las mujeres al conocimiento, en particular la de aquellas monjas que crearon lazos trasatlánticos poco estudiados hasta el momento. En su ensayo, Jorge Gutiérrez Reyna llama la atención sobre la influencia que la famosa religiosa española sor María de Jesús de Ágreda (1602-1665) ejerció sobre Primero sueño de sor Juana Inés de la Cruz (1648-1695). Además, propone que la obra principal de sor María, la Mistica Ciudad de Dios, es un referente para la escritura de sor Juana, en especial en su texto menos conocido Ejercicios de la Encarnación; en estas creaciones tanto el proceso de gestación de Jesús como el papel de María en tal labor adquieren una centralidad negada en el canon patriarcal. En opinión del investigador, sor Juana toma como referencia a la monja de Ágreda porque ambas comparten una percepción empoderada del alma femenina cuando esta accede a una visión de la totalidad.

Sin embargo, no todas las voces de mujeres nos han llegado a través de la escritura, sino también de la oralidad, en especial en las denuncias sobre damas que ejercían oficios tradicionalmente femeninos, pero que el Santo Oficio consideraba potencialmente peligrosos. Alberto Ortiz y Brenda Ortiz Coss nos acercan a la persecución inquisitorial de las parteras, cuyo origen se encuentra en la relación que las autoridades establecen entre esta profesión y el mito de la brujería. Para ello estudian varios casos que tienen lugar durante la época del virreinato de la Nueva España y que no son sino prueba de la vigilancia que el Tribunal ejercía sobre las actividades médicas que, de acuerdo a sus preceptos, ponían en riesgo las normas y la moral cristianas. Los investigadores sostienen que los sacerdotes y prelados, debido al peso de la tradición misógina, enlazaban la práctica de las parteras con la adivinación y la hechicería. También es preciso considerar un sesgo de género, puesto que las sanadoras suponían una competencia para los doctores, titulados por la universidad, que ejercían la medicina autorizada. Este estudio dialoga con las ideas de Barbara Ehrenreich y Deidre English, para quienes "la mayor parte de las mujeres condenadas como brujas eran simplemente sanadoras no profesionales al servicio de la población campesina” (21). De acuerdo con estas investigadoras, su eliminación en Europa "tuvo como contrapartida la creación de una nueva profesión médica masculina, bajo la protección y patrocinio de las clases dominantes" (21). Sin embargo, en la Nueva España, a pesar de las sospechas, estas mujeres siguieron ejerciendo su profesión y gozaron en sus buenos momentos del reconocimiento de la comunidad.

Entre las damas en situación de vulnerabilidad se sitúan aquellas acusadas ante el Santo Oficio por el ejercicio de prácticas supersticiosas. En "Muñecos para hechizar ...., Cecilia López Ridaura examina expedientes inquisitoriales del siglo XVIII, que se produjeron en el obispado de Michoacán (Nueva España), en los que varias mujeres fueron denunciadas por el uso de la magia simpatética. Este trabajo forma parte de un proyecto de investigación que tiene como objeto hacer un catálogo de los casos de brujería y hechicería entresacados de los expedientes de la serie Inquisición que se resguardan en el Archivo Histórico Casa de Morelos (AHCM) en la ciudad de Morelia. De unos 60 expedientes que tratan asuntos relacionados con esta temática, Cecilia López Ridaura localiza varios casos en los que se menciona el uso de estos objetos. Las protagonistas de este estudio son la mulata María Guadalupe, la mestiza Isabel Mengosa y la negra libre María Manuela Chavira, entre otras. Por un lado, el ensayo nos aclara distintas prácticas de magia simpatética con muñecos o fetiches, que las damas usaban para adquirir poder, en especial sobre los hombres, en una sociedad que las mantenía en una posición de inferioridad. Por otro lado, nos revela que no solo el género femenino prima entre las acusadas por el ejercicio de este tipo de prácticas, sino que los cuerpos de estas mujeres se vuelven más vulnerables cuando pertenecen a una etnia que no es la peninsular.

Sobre la precariedad ante la ley de las mujeres afrodescendientes nos hablan Silvia Ruiz Tresgallo y Cecilia López Badano en su ensayo sobre el cuento interpolado “Un negocio con Juana García” de Juan Rodríguez Freyle. Las académicas se acercan a este texto desde una perspectiva interseccional (Crenshaw), puesto que la 
confluencia entre género y etnia que atraviesa el cuerpo de la protagonista resulta clave para que la acusación prospere, como demuestran los procesos de la época. Además, a estas categorías de precariedad se suman otras, como la clase social baja, la falta de filiación a una figura masculina, la profesión de comadrona y la autofinanciación, que constituyen matrices de un perfil criminal que permite señalar qué cuerpos tienen más probabilidades de ser denunciados por la élite y posteriormente eliminados por las autoridades.

La protagonista de este relato, la partera Juana García, es penitenciada y desterrada por la Inquisición bajo acusación de hechicería, dentro del primer auto de fe que tuvo lugar en el Nuevo Reino de Granada (Colombia hoy en día) en el año 1563. Por una parte, el análisis de las investigadoras revela que la afrodescendencia de las protagonistas, Juana y sus hijas, resulta instrumental tanto en la criminalización de sus actividades, relacionadas por los eclesiásticos con la hechicería, como en su expulsión del espacio colonial al que, según las autoridades, no tienen derecho a pertenecer. Por otra parte, consideran que Rodríguez Freyle utiliza a las marginadas de la historia para condenar la corrupción de los varones ilustres en el Nuevo Reino de Granada, una decisión que se sirve del cuerpo y la voz de estas mujeres para beneficiar al autor y que está alejada de la búsqueda de justicia para este colectivo. En las denuncias y procesos seguidos por el Santo Oficio nos encontramos con damas que se resisten a ser definidas por las masculinidades hegemónicas y que, o bien acusan a los mandos que las criminalizan injustamente, como sucede con Juana García, o bien proponen nuevas maneras de entender lo femenino.

Stacey Schlau, en "Magdalenas americanas: 'endemoniadas' novohispanas ante la Inquisición”, analiza el conflicto entre la autoexpresión femenina inspirada en el pensamiento individual y las enseñanzas que la Iglesia católica imponía de manera colectiva a través de las normas y límites de la doctrina. Enfocándose especialmente en la figura de Bárbara de Echegaray, además de en otras endemoniadas novohispanas, investiga las tensiones entre las prácticas sexuales y las normas impuestas por la Iglesia. En opinión de Schlau, mientras que los eclesiásticos culpabilizan a Echegaray a través de una tradición misógina en la que la infestación de su cuerpo por los demonios era un signo inequívoco de su debilidad como mujer, la acusada se apropia del discurso religioso y lo reinterpreta al articularse como la víctima de los ataques del maligno que se manifiestan a través de enfermedades y violencias infligidas a lo largo de su vida. De hecho, en su discurso afirma que lejos de rendirse ante aquellos que la han querido sobajar, como si fuera una figura crística, ha logrado sobreponerse y sobrevivir. La Iglesia no es ajena a las violencias que ha sufrido la joven, sino que es agente de las mismas, puesto que su confesor la disciplina por medio de azotes y traiciona su voto de castidad al mantener relaciones sexuales con ella. Precisamente, uno de los aspectos más interesantes del ensayo es la articulación de la sexualidad, Dios y el demonio en la narrativa de las endemoniadas, porque estas mujeres desafían y reinterpretan los límites de la doctrina en sus propios términos, lo cual debió provocar no poca confusión entre los inquisidores.

No cabe duda de que la espiritualidad femenina tiene un peso enorme en la sociedad barroca americana. Paul Firbas en "Mariana de Oliva, criada india de Santa Rosa de Lima: vida y textos" estudia los documentos preparados en esta ciudad del virreinato del Perú durante el siglo XVII para apoyar la canonización de la mística, así como las primeras hagiografías sobre su figura publicadas en Europa. Al comparar los testimonios de las voces limeñas con las biografías de la terciaria dominica, detecta diferencias que visibilizan la agencia de la devoción popular indígena en la construcción de Rosa como la excelsa patrona de Lima. Es decir, al indagar en estos textos reconstruye la participación de la criada Mariana de Oliva, "india ladina”, en la vida de Rosa y en la producción de su santidad.

Firbas mantiene que, aunque la canonización de la mística supone un proceso de legitimación de los intereses criollos, las narrativas y testimonios desvelan la participación indígena en este proceso. Por ejemplo, algunos archivos estudiados nos acercan a la vida cotidiana de las mujeres indígenas dentro de las casas criollas, en las que, aunque existía una jerarquía de orden español, la convivencia doméstica en la cocina, la oración o las labores de costura generaban aprendizajes bidireccionales en los que se filtraban costumbres y palabras de origen indígena y con ellas su forma de entender el mundo. En este sentido, los textos estudiados nos acercan 
a lo que el investigador califica "como un fenómeno textual y como manifestación de una cultura urbana multiétnica”.

Va resultando evidente que la construcción de la santidad en el espacio americano nos permite identificar tensiones entre grupos étnicos y clases sociales, pero también permite identificar aperturas por medio de espacios de fluidez. El ensayo de Pilar Espitia estudia los casos de Santa Rosa de Lima y San Martín de Porras y, por tanto, la representación de las figuras de santidad como sujetos queer que alteraban y resistían las estructuras coloniales. En la línea de Firbas, la investigadora comparte con el colonialista no solo la premisa multiétnica de la sociedad virreinal, sino también la resistencia al sometimiento español y criollo por medio, en este caso, de la filtración de interpretaciones heterodoxas y, por tanto, disidentes al dogma de la Iglesia. Espitia se pregunta qué hace que Santa Rosa suba tan rápido a los altares, a diferencia de otras religiosas contemporáneas, o cómo San Martín, un afrodescendiente, adquiere tanta fama y veneración.

La académica nos revela el carácter queer del misticismo, ya que este acercamiento a la religión produce un erotismo que desafía tanto los patrones heterosexuales como los esquemas binarios del género. Algunos ejemplos proporcionados por Espitia son: la mujer que ya no es objeto de deseo, sino que puede expresar su pasión hacia Dios de manera abierta, o el varón que enuncia su amor hacia el Amado, insinuando una relación homosexual. Además, en el contexto americano el elemento queer va más allá de las categorías de género y sexualidad, puesto que implica la inclusión de las culturas no peninsulares. En este sentido, la autora especula que la proximidad de Rosa con los indígenas y los esclavos afrodescendientes, es decir, con los marginados, la lleva a tomar brebajes y comidas aderezadas con plantas autóctonas y productos recomendados o proporcionados por estos grupos, los cuales incorpora a sus rituales para devenir en una santidad transcultural o queer. En el caso de San Martín de Porras, el primer santo afroamericano, la hagiografía enlaza su profesión de "barbero, enfermero y cirujano", no solo con sus milagros, sino con las prácticas de la hechicería y el curanderismo propias de la sabiduría popular en la Lima virreinal. La fluidez del misticismo queerifica las estructuras coloniales al generar un contradiscurso que nos invita a replantear nociones fosilizadas sobre este periodo.

También, las prácticas sexuales y corporales heterodoxas que tienen lugar en la época del virreinato de la Nueva España poseen un importante potencial contracultural en que las mujeres y hombres transgresores buscan posibilidades de negociación con las estructuras hegemónicas. Laura A. Lewis, por medio del análisis de documentos primarios y referencias a debates académicos, explora cómo las instituciones disciplinaban una serie de comportamientos disidentes de la cultura impuesta, entre los que se encontraban la homosexualidad, el travestismo y la brujería. La investigadora sugiere que, en la imaginación colonial, los hombres indígenas se relacionaban con frecuencia con lo femenino, un estado que les permitía ser simultáneamente perdonados, por su estatus inferior a la masculinidad hegemónica, y condenados, al tener la potencialidad de contaminar con sus prácticas el cuerpo social. La homosexualidad, así como el uso de un vestuario disidente, por una parte, definían esta condición de diferencia con la cultura criolla, mientras que, por otra parte, fomentaban la ansiedad de las élites que precisaban contener lo que ellos consideraban como una influencia amenazante para su cultura. Si bien españoles y criollos protegen a los indígenas como menores legales bajo el domino de la corona, al mismo tiempo les otorgan poderes diabólicos que poseen la capacidad de incursionar y desestabilizar el cuerpo político colonial. En este espacio híbrido del virreinato, la cultura dominante simultáneamente desprestigia y empodera aquello que considera femenino.

Este dossier ofrece una perspectiva multidisciplinar que abarca las investigaciones de académicos latinoamericanos, españoles y estadounidenses en un intento por explorar los debates entre el género y la cultura colonial, situando la teoría en espacios diversos. A través del estudio de una variedad de documentos, los ensayos abordan los roles históricos y sociales atribuidos y/o impuestos a mujeres, hombres y otras identidades sexogenéricas durante esta época. También, incorporan las consecuencias de las matrices de dominación: por una parte, las violencias que sufren los individuos o comunidades que desafían los roles impuestos y, por otra parte, las resistencias que presentan para alterar las estructuras coloniales y defender, así, 
el derecho a su propia diversidad. Deseamos que estos acercamientos promuevan el interés por la investigación y relectura de textos coloniales desde los estudios de género, los cuales permiten visibilizar el potencial contracultural que reside en las narrativas de este periodo.

\section{Referencias}

Crenshaw, Kimberle. "Demarginalizing the Intersection of Race and Sex: A Black Feminist Critique of Antidiscrimination Doctrine, Feminist Theory and Antiracist Politics". University of Chicago Legal Forum, vol. 1989, n. ${ }^{\circ} 1,1989$, pp. 139-167.

Ehrenreich, Barbara y Deirdre English. Brujas, parteras y enfermeras. Una historia de sanadoras femeninas. 1973. El Rebozo-Palapa Editorial, 2014.

Gómez Suárez, Águeda. “Transculturalidad y órdenes sociosexuales en América”. Trans* Diversidad de identidades y roles de género, coordinado por Andrés Gutiérrez Usillos, Ministerio de Educación, Cultura y Deporte / Museo de América, 2017, pp. 38-47.

Moreno Conde, Margarita. "La delicada frontera entre los sexos en la antigua Grecia". Trans ${ }^{*}$ Diversidad de identidades y roles de género, coordinado por Andrés Gutiérrez Usillos, Ministerio de Educación, Cultura y Deporte / Museo de América, 2017, pp. 66-81.

Licencia Creative Commons CC BY 4.0

Cómo citar: Ruiz Tresgallo, Silvia. “Género y Cultura Colonial”. Cuadernos de Literatura, vol. 25, 2021. htt ps://doi.org/10.11144/Javeriana.cl25.gycc 